\section{Prediction of rock load emphasizing excavation damage of in situ rocks caused by blasting in coal mines}

\author{
Avinash Paul ${ }^{1, *}$, Vemavarapu Mallika Sita \\ Ramachandra Murthy ${ }^{2}$, Amar Prakash ${ }^{1}$ and \\ Ajoy Kumar Singh ${ }^{3}$
}

\begin{abstract}
${ }^{1}$ CSIR-Central Institute of Mining and Fuel Research, Dhanbad 826015 , India

${ }^{2}$ Department of Mining Engineering, IIT Indian School of Mines, Dhanbad 826 004, India

${ }^{3}$ Formerly at CSIR-Central Institute of Mining and Fuel Research,
\end{abstract} Dhanbad 826015 , India

Roof failure in coal mines is strongly related to the frequency of laminations and their movement when the load acts upon them. Detachment of roof bolts from mine roof due to improper estimation of extent of weak zone is one of the major problems in underground coal mines, thus affecting the safety and productivity of workings. The most popular and practised method for roof support design in Indian coal mines is the Central Mining Research Institute-ISM geomechanical classification system. Irrespective of such an established system of support design, accidents due to roof fall still persist. Here we review various available classification systems for rock load estimation and identify their limitations. The study has been extended taking into consideration the case study of KTK-6 incline of Singareni Collieries Company Limited by proposing a modified rock mass classification system based on seismic wave velocity as a key descriptor. A modified rock mass rating (RMR) system $\left(R_{M} R_{\text {dyn }}\right)$ with inclusion of seismic velocity as one of the parameters is proposed for the estimation of rock load. Enhancement in rock load by $20 \%$ has been found for RMR $_{\text {CMRI-ISM values less than }} 40$ according to the new rock load relation. This resulted in under-supporting of the roof and thus might have caused failures. For cases with $\mathbf{R M R}_{\text {CMRI-ISM }}$ values more than 60 , the earlier equation overestimates rock load by about $25 \%$ resulting in over-supporting. Thus, estimation of rock load from the proposed new equation appears to be more rational as it takes into account the actual damage zone.

Keywords: Blasting, coal mines, excavation damage, rock load.

STABILITY analysis of underground opening focuses on the loosened or distressed zone surrounding non-damaged rock. It is of extreme importance that the characteristics of the loosened zone and the intact rock be well known ${ }^{1}$. When an opening is made, the existing stresses prior to

\footnotetext{
*For correspondence. (e-mail: avinashpau102@yahoo.co.in)
}

excavation redistribute and adjust themselves to a new equilibrium condition. These stress changes require displacements to occur and the excavated ground tries to converge towards the opening and leads to bed separation in case of sedimentary rocks ${ }^{2}$. The amount of convergence depends on the host ground characteristics, method of excavation and size of the opening made. Blasting in the development faces in particular causes damage to the rock mass around the opening due to lack of free face and consequent higher-order ground vibrations. Generally, the selection of roof bolt parameters without the knowledge of actual blast damage or weak zone in the coal mine roof leads to roof stability problems ${ }^{3}$. In situ seismic refraction is a technique that can be used in the coal mine roof in order to determine seismic wave velocity and the extent of weak zones in the surrounding rock ${ }^{4}$. A pre- and postsurvey usually identifies the extent of damage zone due to repeated blasting as well as stress-induced dilation. In seismic characterization, the basic procedure is to generate seismic waves by a near surface hammering, and record through geophones the resulting waves which reach the surface of the roof at different places after travelling through different paths. The positions of reflecting and refracting interfaces are deduced by analysis of travel times of the identifiable wave groups ${ }^{5}$.

Rock mass classification systems have constituted an integral part of empirical mine design for over 100 years ${ }^{6}$. The primary objective of all the classification systems is to quantify the intrinsic properties of rock mass based on past experience. The next objective is to examine how external loading influences its behaviour. The earliest reference to the use of rock mass classification for the design of tunnel support in which the rock loads, carried by steel sets, are estimated on the basis of descriptive classification $^{7}$. Since Terzaghi ${ }^{7}$, many classification systems have been proposed. Some of the major classification systems used for coal mines are reviewed and summarized in Table 1, covering their respective merits and demerits.

The main factor which contributes to roof failure in coal mines is the layering of roof rocks. In the process of excavation in rock or coal, thin layers get separated due to redistribution of stresses. In India, Central Mining Research Institute (CMRI-ISM) rock mass rating (RMR) system is being adopted for the design of support system for the last 32 years in underground coal mines. Causewise analysis of fatalities in coal mines as observed in Figure 1 indicates that roof and side falls contribute to about $56 \%$ of the total fatalities, which need attention ${ }^{8}$.

A careful examination of different rock mass classification systems applicable to coal mines reveals the following limitations: (a) Parameter selection (duplication/ redundancy), (b) Weightage assigned and the basis, (c) Relative contribution of parameters to rock load estimation, (d) Time-dependent creep, (e) Repeated cycles of blasting and its effect and (f) In situ characterization of rock mass (cross-bedding, rider seams, clay reins). 


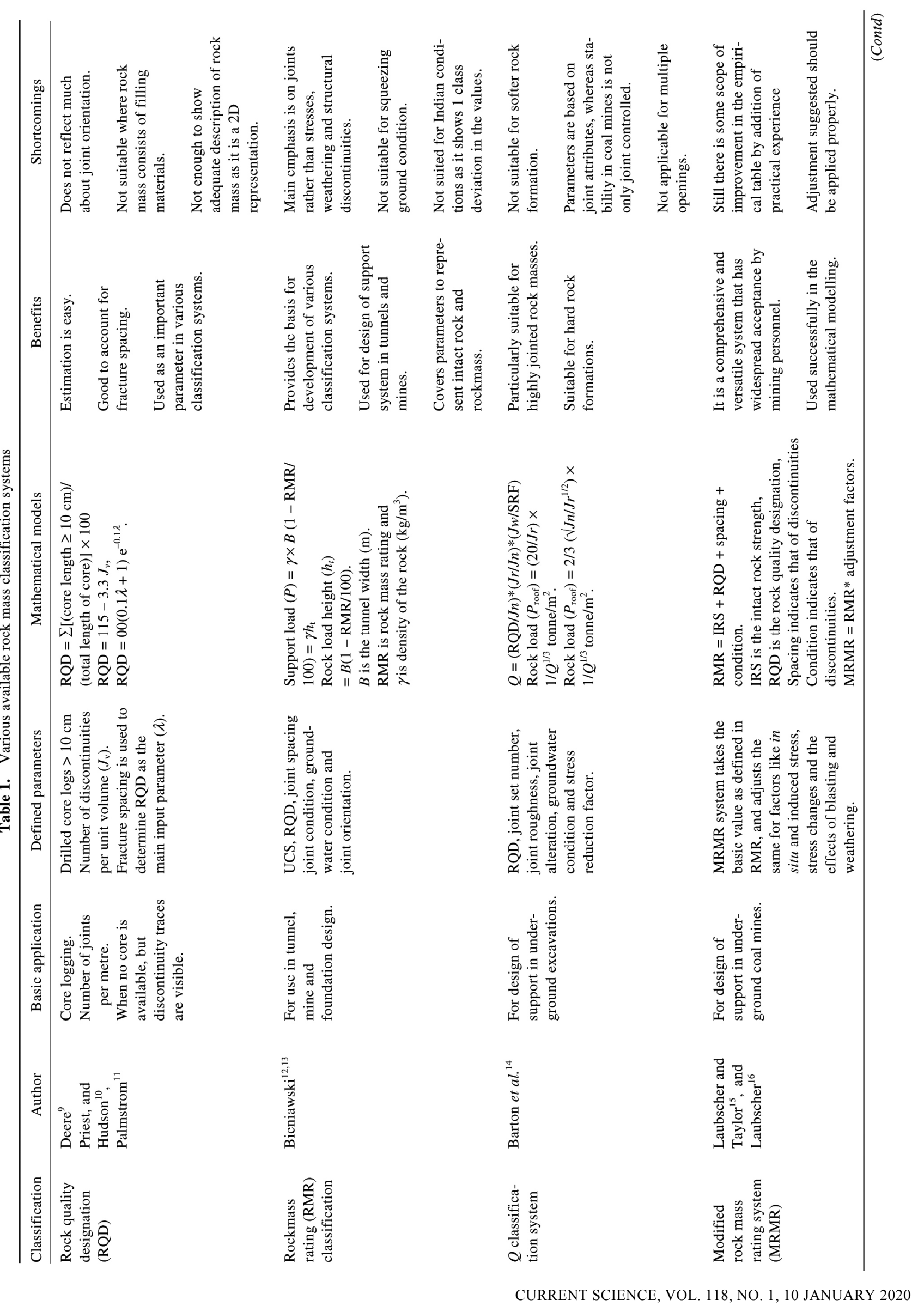




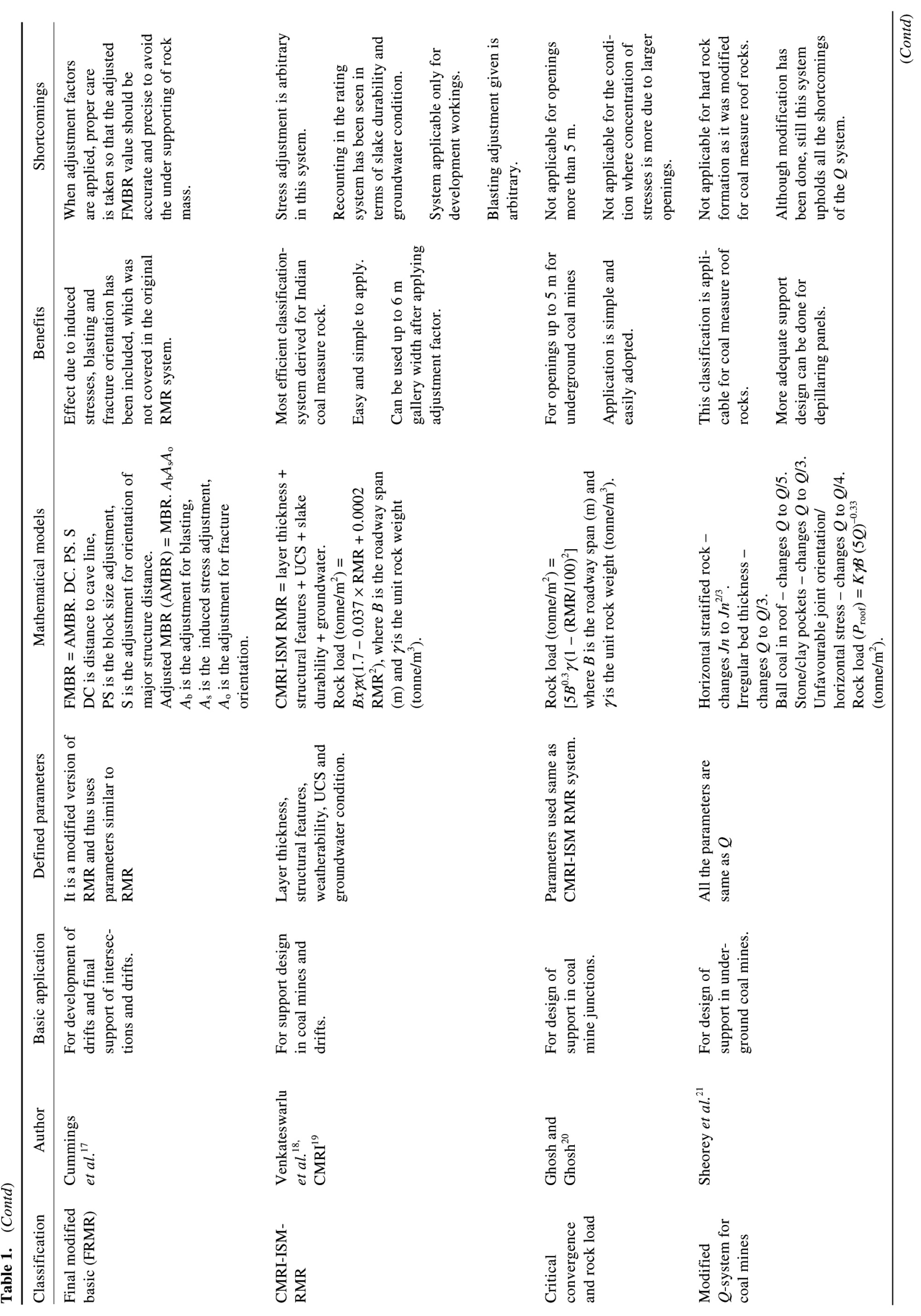

CURRENT SCIENCE, VOL. 118, NO. 1, 10 JANUARY 2020 

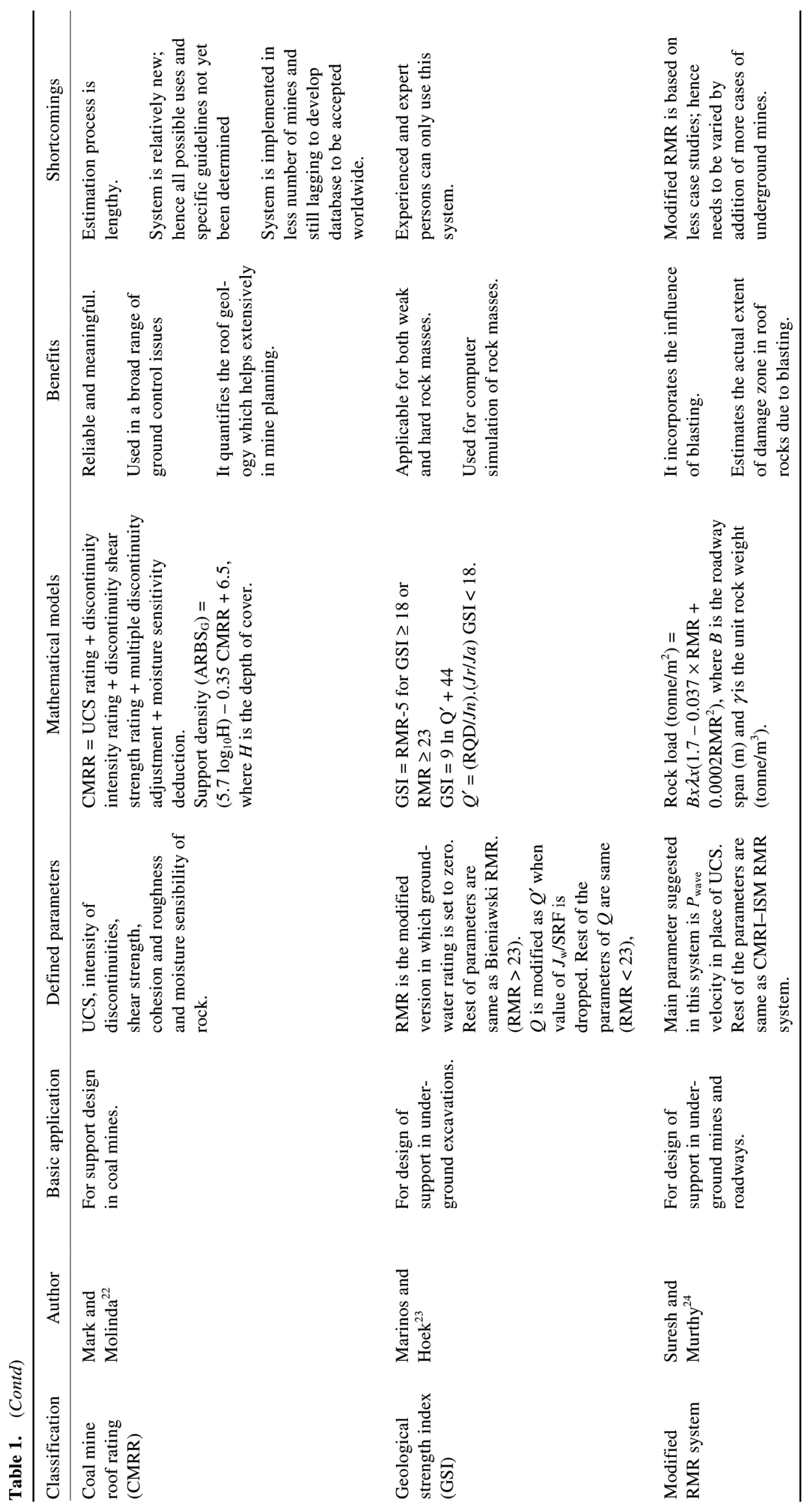
However, after analysis of the rock loads estimated using the CMRI-ISM RMR, it was observed that the present system underestimates rock loads for RMR values below 40 and overestimates when RMR values are more than 40. Considering these factors, it was felt necessary to revisit the existing CMRI-ISM RMR system and suggest suitable modifications to fill the gaps identified.

Keeping in view the shortcomings of modified RMR system, in-depth studies were conducted in the Indian coal mines by considering more cases.

CMRI has developed a classification system for estimation of support requirements in Indian underground coal mine roadways. This approach has been successfully applied to 400-odd coal mines covering almost all the coalfields with varying geo-mining conditions and presently forms the prime basis for estimation of rock load, design and selection of supports in underground coal mine roadways in the country.

Based on the literature survey, detailed geotechnical studies and statistical analysis, five major parameters were identified to yield RMR. For simplicity, the minimum and maximum values of RMR were taken as 0 and 100 respectively. Table 2 provides the individual parameters and their maximum rating based on their influence on roof stability.

Table 3 shows the parameter-wise absolute values and their respective ratings. Weighted RMR was developed considering the number of rock layers in the roof up to a height of $2 \mathrm{~m}$. The adjustment to be applied for RMR is based on the various geo-mining conditions.

Table 2. Maximum ratings for RMR parameters for CMRI-ISM RMR system

\begin{tabular}{lc}
\hline Parameter & $\begin{array}{c}\text { Maximum } \\
\text { rating }\end{array}$ \\
\hline Layer thickness $(\mathrm{cm})$ & 30 \\
Structural features (structural indices) & 25 \\
Weatherability $(\%$ first cycle slake durability index $)$ & 20 \\
Compressive strength $\left(\mathrm{kg} / \mathrm{cm}^{2}\right)$ & 15 \\
Groundwater seepage rate $(\mathrm{ml} / \mathrm{min})$ & 10 \\
\hline
\end{tabular}

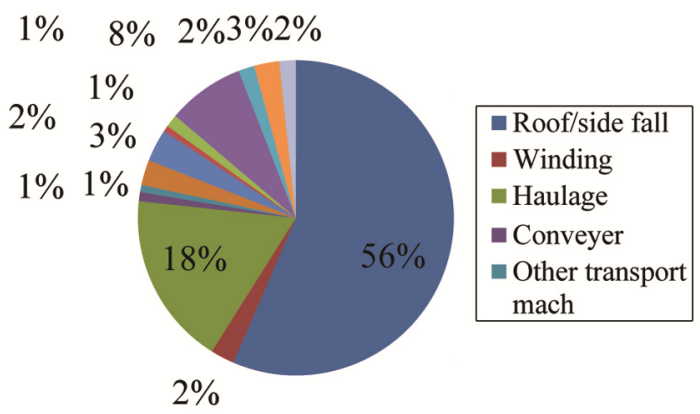

Figure 1. Cause-wise analysis of accidents in underground coal mines of India (after Mandal and Sengupta ${ }^{8}$.
The adjusted RMR was used for estimation of rock load in galleries and junctions from the following equations

Rock load in gallery (tonne $/ \mathrm{m}^{2}$ )

$$
=B D\left(1.7-0.037 \mathrm{RMR}+0.0002 \mathrm{RMR}^{2}\right) .
$$

Rock load in junctions (tonne $/ \mathrm{m}^{2}$ )

$$
=\left[5 B^{0.3} D\left(1-(\mathrm{RMR} / 100)^{2}\right] .\right.
$$

Here RMR is rock mass rating, $B$ the roadway width (m) and $D$ is the dry density (tonne $/ \mathrm{m}^{3}$ ) of rock.

Let us consider the roof of an underground development opening consisting of three layers with $P$-wave velocities $V_{0}, V_{1}$ and $V_{2}\left(V_{2}>V_{1}>V_{0}\right)$ (Figure 2$)$. The lower layer, being close and exposed to blasting is relatively more disturbed and has a $P$-wave velocity $V_{0}$. The second layer is relatively less disturbed and has velocity $V_{1}$ while the uppermost layer is strong and has a $P$-wave velocity $V_{2}$. The thickness of the first and second layers is $z_{0}$ and $z_{1}$ respectively. Figure 3 explains the principle of seismic refraction technique. A seismic wave is generated at point $S$ on the roof surface and energy travels out from it in hemispherical wave fronts. A geophone is located at point $F$ on the roof surface at a distance $(x)$ from the source $S$ to receive the signals. If $x$ is small, the first wave to arrive at $F$ will be the direct wave that travels horizontally at a velocity $V_{0}$. At greater distance, the wave that arrives at point $F$ is the indirect or refracted wave travelling up, along and down with the velocities $V_{0}, V_{1}, V_{2}$ because the time gained in travel through the higher velocity material makes for the longer path (see Figure 3 ). The depth of weak zone is determined using the timedistance plot of direct and refracted paths of wave travel (Figure 4).

Travel time for the first layer is computed as given below

$$
\begin{aligned}
T_{\mathrm{AB}} & =A B / V_{0}=z_{0} / V_{0} \cos i_{1} \\
& =z_{0} /\left[V_{0}\left(1-\left(V_{0} / V_{1}\right)^{2}\right)^{1 / 2}\right]=T_{\mathrm{EF}} .
\end{aligned}
$$

Similarly, for travelling of the legs $B C$ and $D E$, i.e. crossing the middle layer the time can be computed as

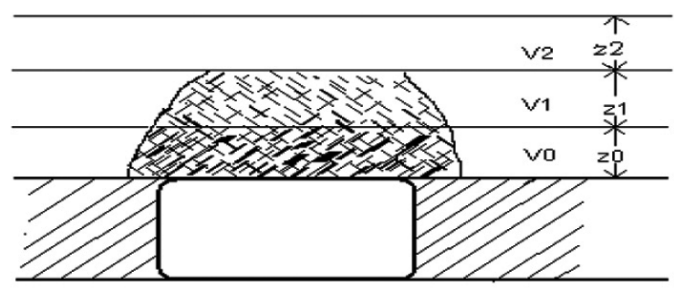

Figure 2. Sectional view of weak zone in the roof. 
Table 3. Rating for RMR parameters

\begin{tabular}{llccccc}
\hline Parameter & \multicolumn{5}{c}{ Range of values } \\
\hline Layer thickness (cm) & Range & $<2.5$ & $2.5-7.5$ & $7.5-20$ & $20-50$ & $>50$ \\
& Rating & $0-5$ & $6-12$ & $13-20$ & $21-26$ & $27-30$ \\
Structural features (index) & Range & $>14$ & $11-14$ & $7-11$ & $4-7$ & $0-3$ \\
& Rating & $0-4$ & $5-10$ & $11-16$ & $17-21$ & $22-25$ \\
Weatherability $(\%)$ & Range & $<60$ & $60 \leq 85$ & $85 \leq 97$ & $97 \leq 99$ & $>99$ \\
& Rating & $0-3$ & $4-8$ & $9-13$ & $14-17$ & $18-20$ \\
Strength of rock $\left(\mathrm{kg} / \mathrm{cm}^{2}\right)$ & Range & $<100$ & $100-300$ & $300-600$ & $600-900$ & $>900$ \\
& Rating & $0-2$ & $3-6$ & $7-10$ & $11-13$ & $14-15$ \\
Groundwater Seepage rate $(\mathrm{ml} / \mathrm{min})$ & Range & $>2000$ & $200-2000$ & $20-200$ & $0-20$ & Dry \\
& Rating & $0-1$ & $2-4$ & $5-7$ & $8-9$ & 10 \\
\hline
\end{tabular}

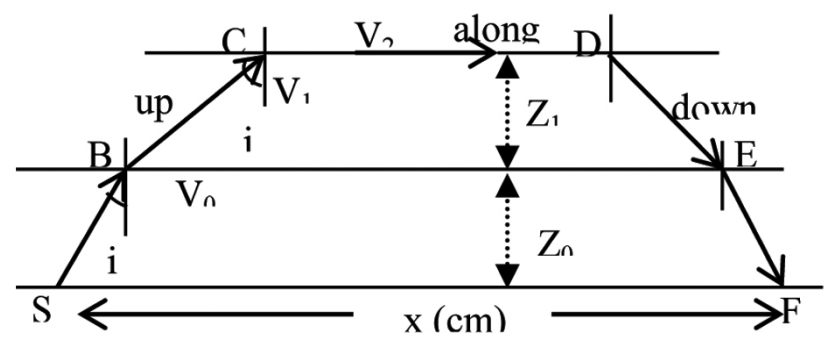

Figure 3. Principle of seismic refraction in three-media case.

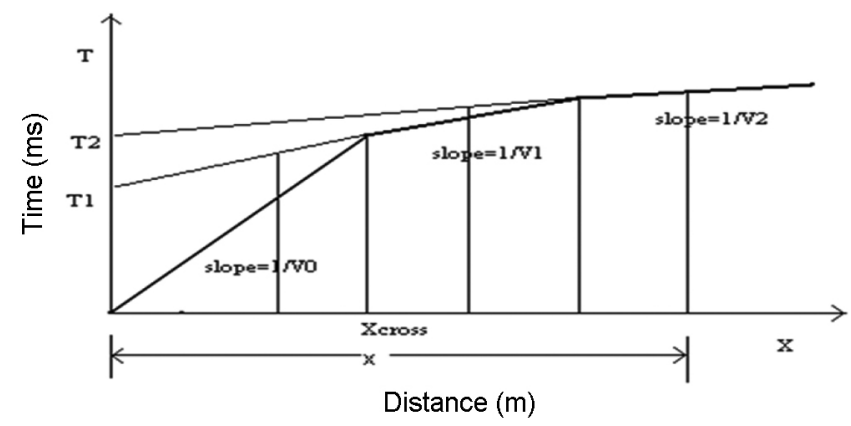

Figure 4. Time-distance plot.

$$
\begin{aligned}
T_{\mathrm{BC}} & =B C / V_{1}=z_{1} / V_{1} \cos i_{2} \\
& =z_{1} /\left[V_{1}\left(1-\left(V_{1} / V_{2}\right)^{2}\right)^{1 / 2}\right]=T_{\mathrm{DE}} .
\end{aligned}
$$

The time for the segment of path $C D$ with velocity $V_{2}$ is $C D / V_{2}$. The expression for travel time from $S$ to $F$ is

$$
\begin{aligned}
T= & T_{\mathrm{AB}}+T_{\mathrm{BC}}+T_{\mathrm{CD}}+T_{\mathrm{DE}}+T_{\mathrm{EF}} \\
=2 & z_{0} /\left[V_{0}\left(1-\left(V_{0} / V_{2}\right)^{2}\right)^{1 / 2}\right] \\
& \quad+2 z_{1} /\left[V_{1}\left(1-\left(V_{1} / V_{2}\right)^{2}\right)^{1 / 2}\right]+C D / V_{2} .
\end{aligned}
$$

where $\quad C D=x-2 z_{0} \quad \tan i_{1}-2 z_{1} \quad \tan i_{2}=x-2 z_{0} V_{0} /$ $\left[V_{2}\left(1-\left(V_{0} / V_{2}\right)^{2}\right)^{1 / 2}\right]-2 z_{1} V_{1} /\left[V_{2}\left(1-\left(V_{1} / V_{2}\right)^{2}\right)^{1 / 2}\right]$.

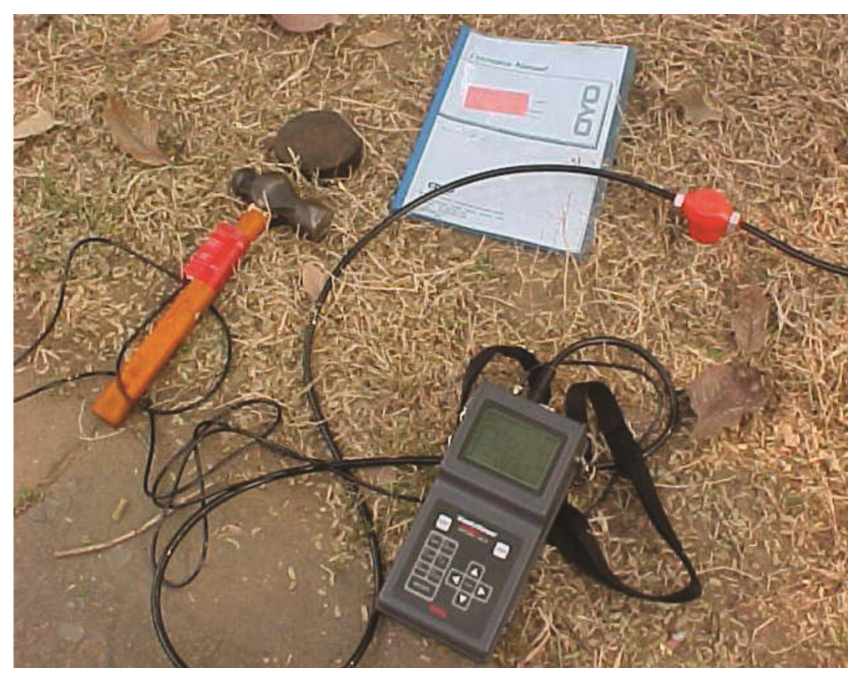

Figure 5. Instrument set-up for seismic imaging technique.

Rearranging the terms, time is expressed as

$$
\begin{aligned}
T & =x / V_{2}+2 z_{0}\left(V_{2}^{2}-V_{0}^{2}\right)^{1 / 2} / V_{2} V_{0} \\
& +2 z_{1}\left(V_{2}^{2}-V_{1}^{2}\right)^{1 / 2} / V_{1} V_{2} \\
z_{0} & =T_{i} / 2\left[V_{1} V_{0} /\left(V_{1}^{2}-V_{0}^{2}\right)^{1 / 2}\right] .
\end{aligned}
$$

The overall travel time of the wave along the top of the $V_{2}$ zone is shown in Figure 3. The portion of the timedistance curve as shown in Figure 4 corresponding to the first arrival of this wave is a straight line with slope $1 / V_{2}$ and an intercept time expressed as

$$
\begin{aligned}
T_{i 2}=T & -x / V_{2}=2 z_{0}\left(V_{2}^{2}-V_{0}^{2}\right)^{1 / 2} / V_{2} V_{0} \\
& +2 z_{1}\left(V_{2}^{2}-V_{1}^{2}\right)^{1 / 2} / V_{1} V_{2} .
\end{aligned}
$$

Solving for $z_{1}$, one obtains

$$
\begin{aligned}
z_{1}= & 1 / 2\left[T_{i 2}-2 z_{0}\left(V_{2}^{2}-V_{0}^{2}\right)^{1 / 2} / V_{2} V_{0}\right] \\
& \times\left[V_{1} V_{2} /\left(V_{2}^{2}-V_{1}^{2}\right)^{1 / 2}\right] .
\end{aligned}
$$

CURRENT SCIENCE, VOL. 118, NO. 1, 10 JANUARY 2020 
RESEARCH COMMUNICATIONS

Table 4. Determination of CMRI-ISM RMR at KTK-6 incline mine

\begin{tabular}{|c|c|c|c|c|c|c|c|c|}
\hline \multirow{3}{*}{$\begin{array}{l}\text { Parameters } \\
\text { Rock type }\end{array}$} & \multicolumn{2}{|c|}{ First bed } & \multicolumn{2}{|c|}{ Second bed } & \multicolumn{2}{|c|}{ Third bed } & \multicolumn{2}{|c|}{ Fourth bed } \\
\hline & \multicolumn{2}{|c|}{$\begin{array}{c}\text { Coarse-grained } \\
\text { sandstone, greyish-white }\end{array}$} & \multicolumn{2}{|c|}{$\begin{array}{c}\text { Coarse-grained sandstone, } \\
\text { greyish-white }\end{array}$} & \multicolumn{2}{|c|}{$\begin{array}{l}\text { Medium to coarse-grained } \\
\text { sandstone, greyish-white }\end{array}$} & \multicolumn{2}{|c|}{$\begin{array}{l}\text { Medium to coarse-grained } \\
\text { sandstone, greyish-white }\end{array}$} \\
\hline & \multicolumn{2}{|c|}{0.60} & \multicolumn{2}{|l|}{0.50} & \multicolumn{2}{|c|}{0.40} & \multicolumn{2}{|c|}{0.50} \\
\hline Bed thickness (m) & Value & Rating & Value & Rating & Value & Rating & Value & Rating \\
\hline Layer thickness $(\mathrm{cm})$ & 12 & 15 & 20 & 20 & 15 & 17 & 20 & 20 \\
\hline Structural features & 12 & 6 & 12 & 6 & 12 & 6 & 12 & 6 \\
\hline Slake durability index (\%) & 97 & 14 & 75 & 6 & 56 & 3 & 55 & 3 \\
\hline Rock strength $\left(\sigma_{\mathrm{c}} ; \mathrm{kg} / \mathrm{cm}^{2}\right)$ & 849 & 12 & 151 & 4 & 83 & 2 & 131 & 3 \\
\hline Groundwater seepage rate $(\mathrm{ml} / \mathrm{min})$ & 500 to 6000 & 0 & 500 to 6000 & 0 & 500 to 6000 & 0 & 500 to 6000 & 0 \\
\hline Total RMR & 47 & & 36 & & 28 & & 32 & \\
\hline
\end{tabular}

The depth to the upper interface is the sum of $z_{1}$ and $z_{0}$, where $z_{0}$ is computed by the two-media formula using the slopes of the first two segments of the time-distance curve and intercept of the second segment. The total depth of weak zone in the roof

$$
z=z_{0}+z_{1}
$$

The seismic characterization of coal mine roof was done using digital seismograph consisting of three components (Handy viewer McSEIS-3 (model-1817)). It is small in size and light in weight, being capable of not only displaying the wave-form data of three components on its sizable LCD equipped with back light, but also for data storage supported by its memory card and the data transfer to the personal computer through its serial link (Figure 5).

The study was conducted at the KTK-6 incline mine of Singareni Collieries Company Limited. The studied site was at $13 \mathrm{LN} / \mathrm{B}$, where the immediate roof of the mine was composed of medium-grained sandstone. Random joints with occasional slips were observed in all the four beds of sandstone within the bolting horizon of $2 \mathrm{~m}$. Heavy seepage of water was also observed.

For stability evaluation of underground mine roadways of a seam, RMR and rock load were determined applying the CMRI-ISM RMR system. The average layer thickness in the coarse-grained sandstone varied from 12 to $20 \mathrm{~cm}$ whereas in medium-grained sandstone it varied from 15 to $20 \mathrm{~cm}$. The roof was dripping in nature. Table 4 gives the different rock mass parameters observed with their respective ratings.

The combined RMR can be determined using the following equation

Combined/weighted $\left(\mathrm{RMR}_{\mathrm{W}}\right)=\Sigma(\mathrm{RMR}$ of each bed $\times$ bed thickness $) / \Sigma($ thickness of each bed $)$.

After adjusting RMR for blasting-off solid the adjusted RMR was 33. Thus, the adjusted RMR will be 33 class $\mathrm{IV}(\mathrm{B})$, indicating poor roof condition.

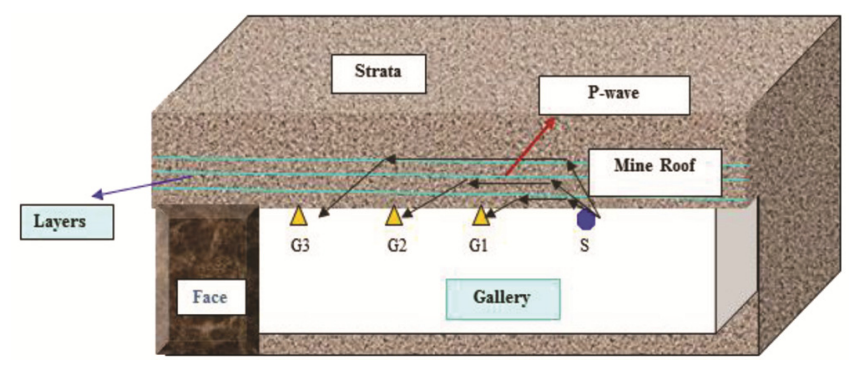

Figure 6. Sectional view of the seismic imaging technique in a mine gallery.

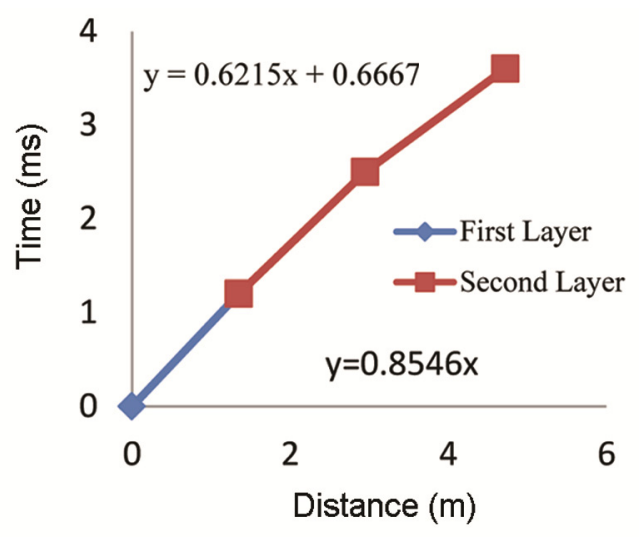

Figure 7. Time-distance curve beyond the green roof.

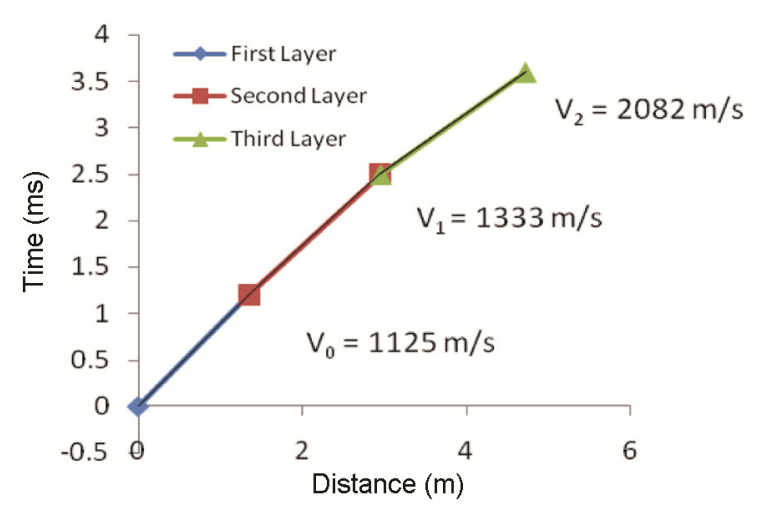

Figure 8. Time-distance curve within the green roof $(7.65 \mathrm{~m}$ from the face). 
Table 5. Average first arrival times in seismic imaging within and beyond the green roof

\begin{tabular}{lcc}
\hline Distance $(\mathrm{m})$ & $\begin{array}{c}\text { Beyond the green roof }(>9 \mathrm{~m}): \\
\text { Average first arrival time }(\mathrm{ms})\end{array}$ & $\begin{array}{c}\text { Within the green roof }(<9 \mathrm{~m}): \\
\text { Average first arrival times }(\mathrm{ms})\end{array}$ \\
\hline 0 & 0 & 0 \\
1.35 & 1.2 & 1.20 \\
2.95 & 2.5 & 2.40 \\
4.72 & 3.6 & 3.25 \\
\hline
\end{tabular}

Table 6. RMR determined using seismic imaging technique

\begin{tabular}{|c|c|c|c|c|c|c|c|c|}
\hline \multirow{3}{*}{$\begin{array}{l}\text { Parameters } \\
\text { Rock type }\end{array}$} & \multicolumn{2}{|c|}{ First bed } & \multicolumn{2}{|c|}{ Second bed } & \multicolumn{2}{|c|}{ Third bed } & \multicolumn{2}{|c|}{ Fourth bed } \\
\hline & \multicolumn{2}{|c|}{$\begin{array}{c}\text { Coarse-grained } \\
\text { sandstone, greyish-white }\end{array}$} & \multicolumn{2}{|c|}{$\begin{array}{c}\text { Coarse-grained sandstone, } \\
\text { greyish-white }\end{array}$} & \multicolumn{2}{|c|}{$\begin{array}{l}\text { Medium to coarse-grained } \\
\text { sandstone, greyish-white }\end{array}$} & \multicolumn{2}{|c|}{$\begin{array}{l}\text { Medium to coarse-grained } \\
\text { sandstone, greyish-white }\end{array}$} \\
\hline & \multicolumn{2}{|c|}{0.60} & \multicolumn{2}{|l|}{0.50} & \multicolumn{2}{|c|}{0.40} & \multicolumn{2}{|c|}{0.50} \\
\hline Bed thickness (m) & Value & Rating & Value & Rating & Value & Rating & Value & Rating \\
\hline Layer thickness, (cm) & 12 & 15 & 20 & 20 & 15 & 17 & 20 & 20 \\
\hline Structural features & 12 & 6 & 12 & 6 & 12 & 6 & 12 & 6 \\
\hline Slake durability index $(\%)$ & 97 & 14 & 75 & 6 & 56 & 3 & 55 & 3 \\
\hline$P$-wave velocity $(\mathrm{m} / \mathrm{s})$ & 1125 & 6 & 1333 & 7 & 2082 & 11 & 2082 & 11 \\
\hline Groundwater seepage rate $(\mathrm{ml} / \mathrm{min})$ & 500 to 6000 & 0 & 500 to 6000 & 0 & 500 to 6000 & 0 & 500 to 6000 & 0 \\
\hline Total $\mathrm{RMR}_{\mathrm{dyn}}$ & 41 & & 39 & & 37 & & 40 & \\
\hline
\end{tabular}

The rock load in the development galleries of KTK-6 incline mine was 5.22. Seismic imaging of coal mine roof was done, where mine development by blasting-off solid was in progress. The study was conducted at the location of heavy water seepage. RMR of the seam was calculated as 33 (poor roof condition) and rock load was 5.22 tonne $/ \mathrm{m}^{2}$, estimated using CMRI-ISM geomechanical classification approach. The seismic velocity of the roof was determined in the green roof (within $9 \mathrm{~m}$ from the face) and beyond the green roof.

A weak zone exists around an underground structure owing to excavation by blasting and stress release after excavation. For determining the extent of damage in the mine roof, seismic imaging was done (Figure 6). The average first arrival times were computed to plot (Table 5) time-distance graphs (Figures 7 and 8 ). The $P$-wave velocities, calculated from time-distance graphs, were used to determine the depth of damage of the excavation zone.

From Figure 7, the $P$-wave velocity of different layers in the roof can be calculated as follows: slope of first line $=0.854$; slope of second line $=0.621$; the intercept time $=0.666 \mathrm{~ms}$ (milli second).

The $P$-wave velocity of the layer is given by the inverse of the slope of the line.

Thus, velocity of the first layer, $V_{0}=1 /$ slope of first line $=1 / 0.8546=1.170 \mathrm{~m} / \mathrm{ms}=1170 \mathrm{~m} / \mathrm{s}$.

Velocity of the second layer, $V_{1}=1 /$ slope of second line $=1 / 0.565=1.609 \mathrm{~m} / \mathrm{ms}=1609 \mathrm{~m} / \mathrm{s}$.

From above $P$-wave velocities of the mine roof, depth of excavation zone can be calculated as follows: Intercept time, $T_{i}=0.6667 \mathrm{~ms}$.

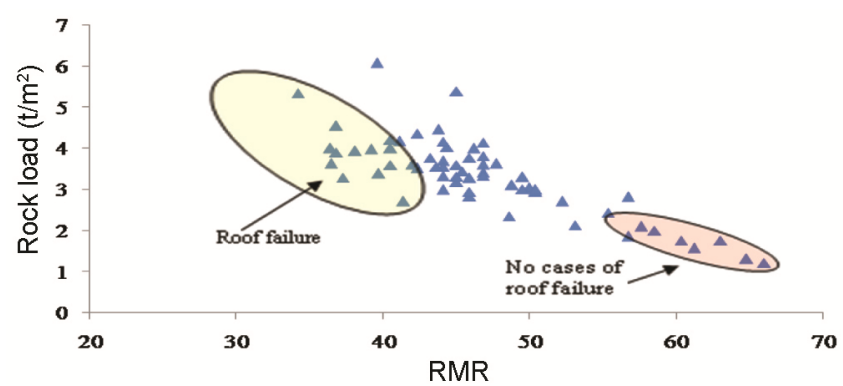

Figure 9. Rock load under different roof conditions.

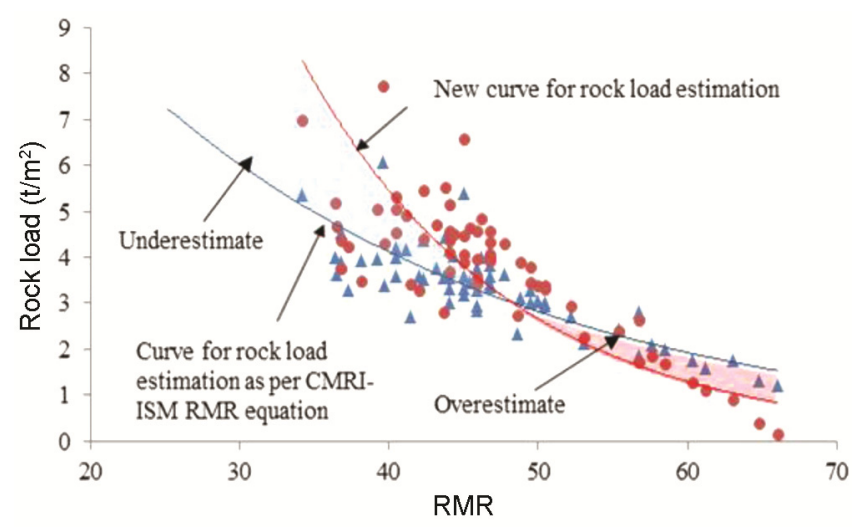

Figure 10. Under and overestimation of rock load by CMRI-ISM RMR system.

Depth of the damage zone can be calculated as $z_{0}=0.57 \mathrm{~m}$ (from eq. (3)).

From Figure 8, the velocities of different layers of the roof can be calculated as mentioned earlier. The velocities 
of within green roof $\left(7.65 \mathrm{~m}\right.$ from the face) are $V_{0}=$ $1125 \mathrm{~m} / \mathrm{s}, V_{1}=1333 \mathrm{~m} / \mathrm{s}, V_{2}=2082 \mathrm{~m} / \mathrm{s}$.

The intercept times are $T_{1}=0.1875 \mathrm{~ms} ; T_{2}=$ $0.9833 \mathrm{~ms}$.

The depth of first layer is given by $z_{0}=0.20 \mathrm{~m}$ (from eq (3)).

The depth of second layer is given by $z_{1}=0.60 \mathrm{~m}$ (from eq. (4)).

Then the total depth of the weak zone in the roof, $z=0.794 \mathrm{~m}=0.80 \mathrm{~m}$ (from eq. (5)).

The depth of the weak zone as determined by equation (3) beyond the green roof was $0.60 \mathrm{~m}$ and within the green roof, it has increased to $0.80 \mathrm{~m}$. From this analysis, it is clear that the $P$-wave velocities are less within the green roof compared to those beyond the green roof. The length of roof bolt is designed considering the extent of damage in the roof as $0.80 \mathrm{~m}$. Thus, the bolt length was fixed at $1.5 \mathrm{~m}$.

RMR was determined by taking into consideration the $P$-wave velocity in place of compressive strength. Here all the parameters except $P$-wave velocity are directly taken from the CMRI-RMR system. Table 6 gives the RMR values determined using seismic imaging technique $\left(\mathrm{RMR}_{\mathrm{dyn}}\right)$. The combined RMR was 40 and rock load was 4.04 tonne $/ \mathrm{m}^{2}$.

There are a good number of cases of roof failure for RMR values ranging from 30 to 40 due to underestimation of rock load using the CMRI-ISM RMR empirical approach. No case of roof failure was observed for RMR values above 55 due to over prediction of rock load (Figure 9). Blasting effect was incorporated in an arbitrary manner by reducing RMR by $10 \%$, whereas the damage

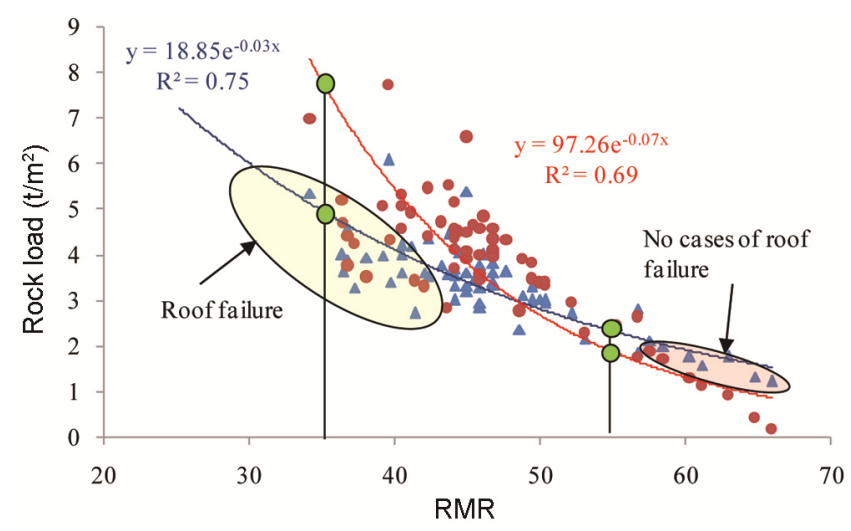

Figure 11. Rock load variation with the proposed RMR.

Table 7. Comparison of RMR and rock loads

\begin{tabular}{lcc}
\hline RMR system & RMR values & Rock load (tonne $/ \mathrm{m}^{2}$ ) \\
\hline CMRI-ISM RMR & 33 & 5.22 \\
RMR $_{\text {dyn }}$ & 40 & 8.35 \\
\hline
\end{tabular}

could be more due to poor roof conditions. Thus, the relationship requires refinement by considering the above related factors, i.e. by enveloping failure cases at lower RMR values and eliminating no failure cases at the higher range of RMR (Figure 10). Rock load for the new curve thus can be expressed as

$$
R L=B^{*} D\left[-763 \mathrm{e}^{-0.007414 \mathrm{RMR}}+766 \mathrm{e}^{-0.007459 \mathrm{RMR}}\right]
$$

where $B$ is the gallery width and $D$ is the density.

For 35 RMR, rock load obtained by CMRI-ISM RMR and the newly proposed RMR equation is 5 and 8 tonne $/ \mathrm{m}^{2}$ respectively, i.e. actual rock load is on the higher side for the same RMR. Thus, the roof needs additional support. Conversely, for higher values of RMR (say 55), rock load variation is about 1 tonne $/ \mathrm{m}^{2}$, i.e. the roof gallery can be kept safe with less support maintaining a constant factor of safety (Figure 11).

An arbitrary assumption of $10 \%$ reduction in RMR in solid blasting can be overcome by determining in situ rock mass condition of the roof using seismic refraction technique. In situ $P$-wave velocity can provide actual rock conditions and roof excavation damage zone. Thus, the newly proposed RMR system can be useful for rational estimation of rock load in development headings.

A comparison was made for low RMR and rock load values determined by the CMRI-ISM RMR and RMR dyn $_{\text {n }}$ (Table 7).

$\mathrm{RMR}_{\text {dyn }}$ was obtained by considering $P$-wave velocity and excluding compressive strength of the rock with a view to include the impact of blasting in in situ rocks. The rock load value for CMRI-ISM RMR system was observed to be on the lower side. The rock load value calculated by $\mathrm{RMR}_{\text {dyn }}$ was high compared to that obtained from CMRI-ISM RMR. CMRI-ISM RMR depicted less value of rock load at lower range in comparison to $\mathrm{RMR}_{\text {dyn }}$ probably leading to roof fall cases (Figure 9). Thus with the newly developed relation by taking $P$-wave into the consideration, precise estimation of rocks can be achieved. This consequently will lead to revised support design, especially at the low RMR range leading to minimization of roof fall. Thus it can be concluded that the $\mathrm{RMR}_{\mathrm{dyn}}$ is more rational and safe, especially for the low RMR range.

The studies were carried out using the existing RMR and new $\mathrm{RMR}\left(\mathrm{RMR}_{\mathrm{dyn}}\right)$. The $\mathrm{RMR}_{\text {dyn }}$ approach clearly indicates the prediction of rock loads in more rational manner with the help of seismic refraction technique. The advantages demonstrated through actual case collected from different coal fields which advocate that $\mathrm{RMR}_{\text {dyn }}$ can be used as a better tool for rock load estimation and support design in poor roof condition, making the working safer than before. This approach would also be helpful in optimizing the support of higher RMR cases. More cases could lead to further fine tuning of the approach. 
1. Paul, A., Singh. A. K., Sinha, A. and Saikia, K., Geotechnical investigation for support design in depillaring panels in Indian coal mines. J. Sci. Ind. Res., 2005, 64, 358-363.

2. Paul, A., Singh, A. K., Rao, D. G. and Kumar, N., Empirical approach for estimation of rock load in development workings of room and pillar mining. J. Sci. Ind. Res., 2009, 68, 214-216.

3. Paul, A., Singh, A. P., John, L. P., Singh, A. K. and Khandelwal, M., Validation of RMR-based support design using roof bolts by numerical modeling for underground coal mine of Monnet Ispat, Raigarh, India - a case study. Arab. J. Geosci., 2011; doi:10.1007/ s12517-011-0313-8.

4. Scott, D. F., Williams, T. J., Denton, D. K. and Friedel, M. J., Seismic tomography as a tool for measuring stress in mines. Min. Eng., 1990, 51, 77-80.

5. Singh, K. K. K., In-seam seismic application for detecting in homogeneities in coal seams - a review. J. Min. Met. Fuel, 1994, 42, 49-54.

6. Ritter, W., Die static der tunnelgewolbe, Springer, Berlin, Germany, 1879.

7. Terzaghi, K., Rock defects and rock loads on tunnel supports. In Rock Tunneling with Steel Supports (eds Proctor, R. V. and White, T. L.), Scientific Research, Academic Publisher, 1946, vol. 1, pp. 17-99.

8. Mandal, A. and Sengupta D., Fatal accidents in Indian coal mines Technical Report No. ASD/99/33, Applied Statics Unit, Calcutta, 1999.

9. Deere, D. U., Technical description of rock cores for engineering purposes. Rock Mech. Eng. Geol., 1964, 1, 17-22.

10. Priest, S. D. and Hudson, J. A., Discontinuity spacing in rock. Rock Mech. Min. Sci. Geomech., 1976, 13, 135-148.

11. Palmstrom, A., The volumetric joint count - a useful and simple measure of the degree of the rock jointing. In Proceedings of the 4th Congress, International Association of Engineering Geology, Delhi, 1982, issue 5, pp. 221-228.

12. Bieniawski, Z. T., Engineering classification of jointed rock mass Trans. S. Afr. Civ. Eng., 1973, 15, 335-344.

13. Bieniawski, Z. T., Rock mass classification in rock engineering. In Exploration for Rock Engineering, Proceedings of the Symposium, (ed. Bieniawski, Z. T.), Balkema, Cape Town, South Africa 1976, vol. 1, 97-106.

14. Barton, N. R., Lien, R. and Lunde, J., Engineering classification of jointed rock mass for the design of tunnel support. Rock Mech., 1974, 6(4), 189-239.

15. Laubscher, D. H. and Taylor, H. W., The importance of geomechanics classification of jointed rock masses in mining operations. In Exploration for Rock (ed. Bieniawski, Z. T.), Balkema, 1976, vol. 1, pp. 119-128

16. Laubscher, D. H., Planning mass mining operations. In Comprehensive Rock Engineering (ed. Hudson, J. A.), Pergamon Press, Oxford, UK, 1993, vol. 2, pp. 547-583.

17. Cummings, R. A., Kendorski, F. S. and Bieniawski, Z. T., Caving rock mass classification and support estimates. USBM contract report I0100103, Engineers International Inc, Chicago, USA, 1982.

18. Venkateswarlu, V., Ghosh, A. K. and Raju, N. M., Rock mass classification for design of roof support - a statistical evaluation of parameters. Min. Sci. Technol., 1989, 8, 97-108.

19. CMRI, Geomechanical classification of roof rocks vis-à-vis roof supports. S\&T Project Report, 1987.

20. Ghosh, C. N. and Ghose, A. K., Estimation of critical convergence and rock load in coal mine roadways - an approach based on rock mass rating. Geotech. Geol. Eng., 1992, 10, 185-202.

21. Sheorey, P. R., Application of modern rock classification in coal mines roadways. In Comprehensive Rock Engineering, Pergamon Press, Oxford, UK, 1993, pp. 411-431

22. Mark, C. and Molinda, G. M., The coal mine roof rating engineering practices. In Coal Operator's Conference, University of
Wollongong \& the Australian Institute of Mining and Metallurgy, Australia (ed. Aziz, N.), 2003, pp. 50-62.

23. Marinos, P. and Hoek, E., GSI: a geologically friendly tool for rock mass strength estimation. In Proceedings of the Geological Engineering 2000 at the International Conference on Geotechnical and Geological Engineering, Melbourne, Australia, 2000, pp. 1422-1446.

24. Suresh, R. and Murthy, V. M. S. R., Seismic characterization of coalmine roof for rock load assessment. In First Indian Mineral Congress, Dhanbad, 2005, pp. 31-46.

ACKNOWLEDGEMENTS. We thank the management of the mines of Singareni Collieries Company Limited (SCCL), South Eastern Coal Feilds, Bharat Cooking Coal Limited, Tata Steel Limited and Mahanadi Coal Fields Limited. We also thank the Director, Indian School of Mines and Director, Central Institute of Mining and Fuel Research, Dhanbad for support. This work is a part of the $\mathrm{PhD}$ thesis of A.P. being carried out at IIT ISM, Dhanbad.

Received 7 May 2019; revised accepted 30 July 2019

doi: $10.18520 / \mathrm{cs} / \mathrm{v} 118 / \mathrm{i} 1 / 123-132$

\section{An early case of lithic recycling in India: evidence from the Acheulian site at Damdongri, Madhya Pradesh}

\author{
S. B. Ota ${ }^{1, *}$, Niharika Srivastava ${ }^{2}$ and \\ Suman Pandey ${ }^{2}$ \\ ${ }^{1}$ Archaeological Survey of India, Takhatmal Colony, Sherpura, \\ Vidisha 464 001, India \\ ${ }^{2}$ Deccan College, Pune 411 006, India
}

Research on recycled lithic artefacts in Indian prehistory is extremely limited when compared to the world scenario. In the present study we group the recycled activity of lithic artefacts into two categories-(1) artefact that is created and recycled during one 'cultural age' and (2) artefact that is created by the 'ancestors' and recycled during subsequent cultural ages. It is a fact that the earliest evidence of recycled artefacts belonging to Acheulian hominin is extremely limited and as such, the Damdongri site in Madhya Pradesh, India is the only Acheulian site where recycled artefacts have been identified pushing back the antiquity of such human behaviour to Acheulian culture for the first time in the country. Keeping in view this uncommon evidence and considering the nature of recycled artefacts from Damdongri, it is clear that recycling of lithic artefacts to put them back to use was uncommon during the Acheulian cultural phase in India. The present evidence from Damdongri is unique, where lithic analysis has shown that recycled activity on lithic artefacts was carried out during the Acheulian cultural phase with no intention

*For correspondence. (e-mail: simadriota@gmail.com) 